\title{
Bradykinin potentially stimulates cell proliferation in rabbit corneal endothelial cells through the ZO-1/ZONAB pathway
}

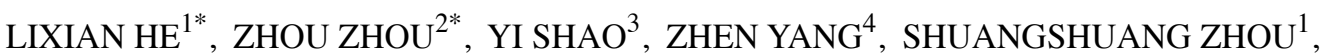 \\ XUEXIANG ZOU ${ }^{1}$, YING ZHOU ${ }^{1}$ and GANG TAN ${ }^{1}$ \\ ${ }^{1}$ Department of Ophthalmology, The First Affiliated Hospital of University of South China; \\ ${ }^{2}$ Medical College, University of South China, Hengyang, Hunan 421001; \\ ${ }^{3}$ Department of Ophthalmology, The First Affiliated Hospital of Nanchang University, \\ Jiangxi Province Clinical Ophthalmology Institute, Nanchang, Jiangxi 330006; \\ ${ }^{4}$ Department of Cardiology, The First Affiliated Hospital of Sun Yat-sen University, \\ Guangzhou, Guangdong 510080, P.R. China
}

Received October 27, 2017; Accepted March 5, 2018

DOI: $10.3892 /$ ijmm.2018.3580

\begin{abstract}
Bradykinin (BK) has been demonstrated to induce proliferation in several types of cell in ex vivo corneas. However, the mechanisms underlying the action of BK on corneal endothelial cells (CECs) remain largely unknown. The present study aimed to investigate the effect of BK on rabbit corneal endothelial cell (RCEC) proliferation, and assess the involvement of the zonula occludens-1(ZO-1)/ZO-1associated nucleic acid binding protein (ZONAB) pathway. Cell proliferation and cell cycle distribution was analyzed following treatment with BK $(0.01,0.1,1.0$ or $10.0 \mu \mathrm{M})$ for the indicated time intervals $(24,48,72$ and $96 \mathrm{~h})$, or following BK treatment combined with transfection of ZONAB-small interfering (si)RNA for $72 \mathrm{~h}$. In addition, the expression of tight junction ZO-1, nuclear ZONAB, proliferating cell nuclear antigen(PCNA) and cyclin D1 were evaluated using western blotting or immunofluorescence. BK treatment was demonstrated to induce time- and concentration-dependent cell proliferation and cell cycle progression, along with the upregulation of tight junction $\mathrm{ZO}-1$ and nuclear ZONAB, as well as PCNA and cyclin D1 protein expression. Furthermore, knockdown with ZONAB-siRNA inhibited cell proliferation, induced cell cycle arrest and downregulated PCNA and cyclin D1 protein expression. ZONAB knockdown therefore successfully reversed the increase in proliferation induced
\end{abstract}

Correspondence to: Professor Gang Tan, Department of Ophthalmology, The First Affiliated Hospital of University of South China, 69 Chuanshan Road, Hengyang, Hunan 421001, P.R. China E-mail: tangang99@hotmail.com

${ }^{*}$ Contributed equally

Key words: bradykinin, zonula occludens-1, ZO-1-associated nucleic-acid-binding protein, corneal endothelial cells, proliferation by BK treatment. Taken together, these results suggested that BK stimulated RCEC proliferation, potentially via the ZO-1/ZONAB pathway. The signaling paradigm disclosed in the present study potentially serves as an important therapeutic target for cornea regeneration and transplantation.

\section{Introduction}

Corneal endothelial cells (CECs) form a single monolayer on the posterior surface of the cornea and serve a pivotal function in the regulation of stromal hydration and the maintenance of corneal transparency (1). Adult human CECs are $\mathrm{G}_{1}$-arrested, leading to a decline of endothelial cell density and subsequent endothelial dysfunction and loss of vision, particularly following injury, aging and surgery (2-4). The conventional approach involves transplantation of healthy donor CECs, but a current global shortage of donor corneas necessitates other options and demands the development of novel therapeutic agents and strategies to induce cell proliferation in the corneal endothelium.

Bradykinin (BK), a nonapeptide, is a major effector of the kallikrein-kinin system that demonstrates a wide range of biological activities, being involved in inflammation, pain, angiogenesis and cell proliferation (5-12). In ocular tissues, BK receptors (B1 and B2 receptors) are abundantly distributed and may trigger ocular allergies and inflammatory responses on the ocular surface (13). BK has been demonstrated to promote cell proliferation through the B2 receptor and epidermal growth factor receptor (EFGR) in ex vivo corneas, including bovine corneal endothelial cells (8), canine/human corneal epithelial cells $(9,10)$ and corneal keratocytes or fibroblasts in the Statens Seruminstitut Rabbit $(11,12)$. However, this phenomenon has not been reported in rabbit CECs, and the exact cellular mechanisms underlying BK-induced proliferation in CECs remain unknown.

Tight junctions (TJs), which are major components of the cell junctional complex, are essential for the barrier 
function of epithelium, epithelial proliferation and differentiation (14,15). Zonula occludens-1 (ZO-1) is a key TJ-associated protein that links junctional membrane proteins to the cytoskeleton (14). ZO-1-associated nucleic-acid-binding protein (ZONAB) is a Y-box transcription factor that is recruited to TJs by binding to the Src homology 3(SH3) domain of ZO-1 (14-16). ZONAB interacts with ZO-1 and regulates the transcriptional activity of cell cycle genes, including cyclin D1 and proliferating cell nuclear antigen (PCNA), that modulate cell cycle progression and cell proliferation (16-18). The ZO-1- and ZONAB-associated pathway (ZO-1/ZONAB pathway) has been demonstrated to regulate proliferation in epithelial cells derived from the renal proximal tubule and retinal pigment epithelium (RPE) (16-20). However, little is known about the effect of ZO-1 and ZONAB on CECs; the involvement of the ZO-1/ZONAB pathway in BK-stimulated cell proliferation remains to be examined.

Therefore, the purpose of the present study was to explore the effect of BK on cell proliferation in cultured rabbit corneal endothelial cells (RCECs), and to determine the contribution of the ZO-1/ZONAB pathway to BK-induced RCEC proliferation. To the best of our knowledge, the present study is the first to demonstrate BK-stimulated cell proliferation and cell cycle progress in RCECs, and that the underlying mechanisms involved the activation of the ZO-1/ZONAB signaling pathway.

\section{Materials and methods}

Animals. A total of 34 New Zealand white rabbits (Experimental Animal Center, University of South China, Hengyang, China; weight, $1.5-2.0 \mathrm{~kg}$; age, 50 days) were employed in the present study. Rabbits were housed in individual cages under standard conditions (room temperature at $25-27^{\circ} \mathrm{C}$, humidity at $45-55 \%$ with $12 \mathrm{~h}$ light/dark cycle) with free access to standard laboratory chow and sterile acidified water. All experimental protocols were conducted in accordance with the Experimental Animal Regulations established by The Ministry of Science and Technology of the People's Republic of China, and the Guidelines for the Care and Use of Laboratory Animals published by the National Institutes of Health (Bethesda, MD, USA) (21). The study received ethical approval from the ethics committee of the University of South China.

Cell culture. Isolation and establishment of RCECs was performed as previously described, with modifications $(22,23)$. Briefly, the rabbit corneal buttons were obtained following enucleation. Corneal endothelia with Descemet's membrane were dissected and peeled off under a stereoscopic dissecting light microscope (SMZ800; Nikon Corporation, Tokyo, Japan). Cells were then incubated in disaggregating solution (300 U type I collagenase and $1 \%$ antibiotic/antimycotic) in Dulbecco's modified Eagle's medium (DMEM; Gibco; Thermo Fisher Scientific, Inc., Waltham, MA, USA) for $3 \mathrm{~h}$ at $37^{\circ} \mathrm{C}$ in $5 \% \mathrm{CO}_{2}$. The medium was changed every other day. When cells reached confluence (within 10-14 days), they were enzymatically detached with $0.25 \%$ trypsin (HyClone; GE Healthcare Life Sciences, Logan, UT, USA) and subcultured. RCECs that had been passaged 2-4 times were used for the following experiments.
Small interfering (si)RNA preparation, screening and transfection. Three siRNA duplexes targeting ZONAB (GenBank accession ID: AF171061.1) were designed using the siRNA Target Finder and Design Tool (http://www.ambion.com; Ambion; Thermo Fisher Scientific, Inc.) and National Center for Biotechnology Information Basic Local Alignment Search Tool. Another scrambled sequence siRNA, with no homology to the rabbit ZONAB gene, was used as a siRNA negative control (NC-siRNA). All siRNAs were commercially synthesized by Sangon Biotech Co., Ltd. (Shanghai, China). The sequences of each siRNA targeting ZONAB, as well as the scramble control were presented in Table I.

Transient siRNA transfection was performed using Lipofectamine 2000 (Invitrogen; Thermo Fisher Scientific, Inc.), according to the manufacturer's protocols, due to the high transfection efficiency and low cytotoxicity of lipofectin transfection (24). In short, three siRNA sequences or the scrambled control siRNA complex ( $5 \mu \mathrm{l}$ of each at the concentration of $20 \mu \mathrm{M}$, diluted with diethyl pyrocabonate-treated water) with transfection reagents were added to cultured cells at $50 \%$ confluence. After $48 \mathrm{~h}$, mRNA or protein was extracted to detect the transfection efficiency. The ZONAB-siRNA that had the maximum inhibition rate was selected and used for further in vitro experiments.

$B K$ administration and experimental groups. In the present study, cells in the logarithmic growth phase were incubated with various concentrations $(0.01,0.1,1.0$ and $10.0 \mu \mathrm{M})$ of BK (Abcam, Cambridge, MA, USA) for the indicated time intervals $(24,48,72$ and $96 \mathrm{~h})$ at $37^{\circ} \mathrm{C}$. The time intervals and concentrations of $\mathrm{BK}$ were selected based on the results of previous studies and were confirmed to effectively induce cell proliferation (9-12). When the cultures reached confluence, cells were plated onto 12 -well culture plates $(1 \mathrm{ml} /$ well $)$ for the measurement of ZO-1 and ZONAB protein expression. RCECs were plated onto 24 -well plates $(0.5 \mathrm{ml} /$ well $)$ for the examination of cell growth and morphology under a phase-contrast microscope (CH2; Olympus Corporation, Tokyo, Japan).

In order to investigate the causal function of ZONABassociated signaling in BK-induced cell proliferation, RCECs were treated with $\mathrm{BK}$ alone, or BK treatment was combined with ZONAB-siRNA transfection. The cells were randomly divided into 6 groups $(n=8$ each) as follows: Control group (neither BK treatment nor ZONAB-siRNA transfection), BK group (treated with $1.0 \mu \mathrm{M} \mathrm{BK}$ ), NC-siRNA group (transfected with NC-siRNA), ZONAB-siRNA group (transfected with the ZONAB-siRNA sequence), NC-siRNA+BK group (1.0 $\mu \mathrm{M}$ BK was administrated to cells transfected with NC-siRNA) and ZONAB-siRNA+BK group (1.0 $\mu \mathrm{M}$ BK was administrated to cells transfected with the ZONAB-siRNA sequence). Cell samples were collected at $72 \mathrm{~h}$. MTT assays were performed to detect cell proliferation, and cell cycle distribution was analyzed using flow cytometry, as subsequently described. ZO-1, ZONAB, PCNA and cyclin D1 protein expression was detected by western blotting, together with immunofluorescence assay for ZONAB.

Cell proliferation assay. Cells ( $5 \times 10^{3} /$ plate) were loaded in 96-well plates, maintained in DMEM with 10\% FBS, and then treated with $0.3 \%$ dimethyl sulfoxide (DMSO) 
Table I. siRNA and RT-PCR primer sequences.

A, siRNA sequences used for ZONAB silencing

ZONAB SiRNA1

ZONAB SiRNA2

ZONAB siRNA3

Scramble control

B, Primer sequences used for RT-PCR analysis of ZONAB
5'-GAAUCAACAAGCAGCCAAUTTdTdT-3' (sense)
5'-AUUGGCUGCUUGUUGCUUCTTdTdT-3' (antisense)
5'-GAUCGGAGAGAUGAAGGAUTTdTdT-3' (sense)
5'-AUCCUUCAUCUCUCCGAUCTT dTdT-3' (antisense)
5'-GGAAUUUGAUGUGGUGGAATTdTdT-3' ( sense)
5'-UUCCACCACAUCAAAUUCCTTdTdT-3' (antisense)
5'-CGAGGAGACUUCCGAAUCUAUdTdT-3' (sense)
5'-ACGUGACACGUUCGGAGAATTdTdT-3' (antisense)

\begin{tabular}{ll}
\hline ZONAB & 5'-GCCATCAAGAAGAATAACCCACG-3' (forward) \\
& 5'-GCGTAACGACTCCCTTCCACA-3' (reverse) \\
$\beta$-actin & 5'-GTTCGAGACCTTCAACACCCC-3' (forward) \\
& 5'-CCGGCCAGCCAGGTCCAGA-3' (reverse)
\end{tabular}

RT-PCR, reverse transcription polymerase chain reaction; siRNA, small interfering RNA; ZONAB, ZO-1-associated nucleic-acid-binding protein.

or BK $(0.01,0.1,1.0$ and $10.0 \mu \mathrm{M})$, or BK $(1.0 \mu \mathrm{M})$ with ZONAB-siRNA or NC-siRNA transfection as aforementioned. At each exact time point $(24,48,72$ and $96 \mathrm{~h})$, cells were treated with MTT reagent $(10 \mu \mathrm{l})$ for $4 \mathrm{~h}$ at $37^{\circ} \mathrm{C}$ and then with $100 \mu 1 \mathrm{DMSO}$ overnight at $37^{\circ} \mathrm{C}$. Absorbance at $490 \mathrm{~nm}$ was measured usinga Bio-Rad microplate reader (Model-680; Bio-Rad Laboratories, Inc., Hercules, CA, USA). Wells containing culture medium but no cells served as controls. All experiments were repeated five times to ensure consistent results.

Flow cytometry. Confluent cells, treated for $72 \mathrm{~h}$, were collected using $0.25 \%$ trypsin, fixed with $70 \%$ absolute ethyl alcohol at $4^{\circ} \mathrm{C}$ overnight, washed twice in $3 \mathrm{ml} \mathrm{PBS}$, and stained in darkness with PBS containing propidium iodide $(50 \mu \mathrm{g} / \mathrm{ml}$; Roche Diagnostics Co., Ltd., Shanghai, China) at $4^{\circ} \mathrm{C}$ for $1 \mathrm{~h}$ and RNAse $\left(100 \mu \mathrm{g} / \mathrm{ml}\right.$; Thermo Fisher Scientific, Inc.) at $37^{\circ} \mathrm{C}$ for $30 \mathrm{~min}$. The samples were then analyzed using a FACSCanto II flow cytometer (BD Biosciences, Franklin Lakes, NJ, USA). Based on DNA content, the percentage of cells in each stage of the cell cycle $\left(\mathrm{G}_{0} / \mathrm{G}_{1}, \mathrm{~S}\right.$ and $\mathrm{G}_{2} / \mathrm{M}$ phases) was calculated using ModFit LT 3.0(Verity Software House, Inc., Topsham, ME, USA).

Semi-quantitative reverse transcription polymerase chain reaction ( $R T-P C R)$. Total RNA was extracted using an RNeasy Mini kit (Invitrogen; Thermo Fisher Scientific, Inc.), and RT was performed using a High Capacity Reverse Transcription kit (Invitrogen; Thermo Fisher Scientific, Inc.) according to the manufacturer's protocol. PCR primers targeting ZONAB were designed and synthesized by Sangon Biotech Co., Ltd and are presented in Table I. Thermocycler conditions were as follows: $10 \mathrm{~min}$ of initial activation at $95^{\circ} \mathrm{C}$, followed by
40 cycles of $15 \mathrm{sec}$ denaturation at $95^{\circ} \mathrm{C}$, and $1 \mathrm{~min}$ annealing and extension at $60^{\circ} \mathrm{C}$. The identity of each PCR product was confirmed by size determination using $2 \%$ agarose gels followed by ethidium bromide staining and the PCR marker, using an EC3 Imaging System (BioImaging Systems; UVP, Inc., Upland, CA, USA). The intensities of the bands were densitometrically quantified using Quantity One 1D software (version 4.6.9, Bio-Rad Laboratories, Inc., Hercules, CA, USA), and $\beta$-actin was used as an internal reference in each reaction.

Western blotting. Confluent cells were washed, scraped, collected, and centrifuged at $226,000 \mathrm{x}$ g for $1 \mathrm{~h}$ at $4^{\circ} \mathrm{C}$ to yield whole cell extract. Nuclear ZONAB protein and cytoplasmic ZO-1 protein were extracted using a Bicinchoninic acid protein assay (Nanjing KeyGen Biotech Co., Ltd.) according to the manufacturer's protocol. Samples (50 $\mu \mathrm{g}$ protein) were denatured, subjected to $10 \%$ SDS-PAGE, and transferred to nitrocellulose membranes. Subsequently, the membrane was blocked with $5 \%$ non-fat milk in TBST (containing $0.2 \%$ Tween-20, $20 \mathrm{mmol} / \mathrm{l}$ Tris- $\mathrm{HCl}$, and $150 \mathrm{mmol} / \mathrm{l} \mathrm{NaCl}$, pH 7.14; non-fat milk, Bio-Rad Laboratories, Inc., Hercules, CA, USA; Tris, Sigma-Aldrich; Merck KGaA, Darmstadt, Germany) for $1 \mathrm{~h}$ at $37^{\circ} \mathrm{C}$, then incubated withanti-ZO-1 (1:500; cat. no. ab-61357, Abcam), anti-ZONAB (1:1,000; cat. no. 40-2800; Invitrogen; Thermo Fisher Scientific, Inc.), anti-PCNA (1:1,000; cat. no. 60097-1-Ig; ProteinTech Group, Inc., Chicago, IL, USA), anti-cyclin D1 (1:1,000; cat. no BS-0623R; BIOSS, Beijing, China) and anti- $\beta$-actin (1:1,000; cat. no. 60008-1-Ig; ProteinTech Group, Inc.) at $4^{\circ} \mathrm{C}$ overnight. The membrane was washed three times, blocked with 5\% non-fat milk in TBST and then incubated with the appropriate horseradish peroxidase-conjugated secondary antibody at a final dilution of 1:6,000 (cat. no. SA00001-2; 

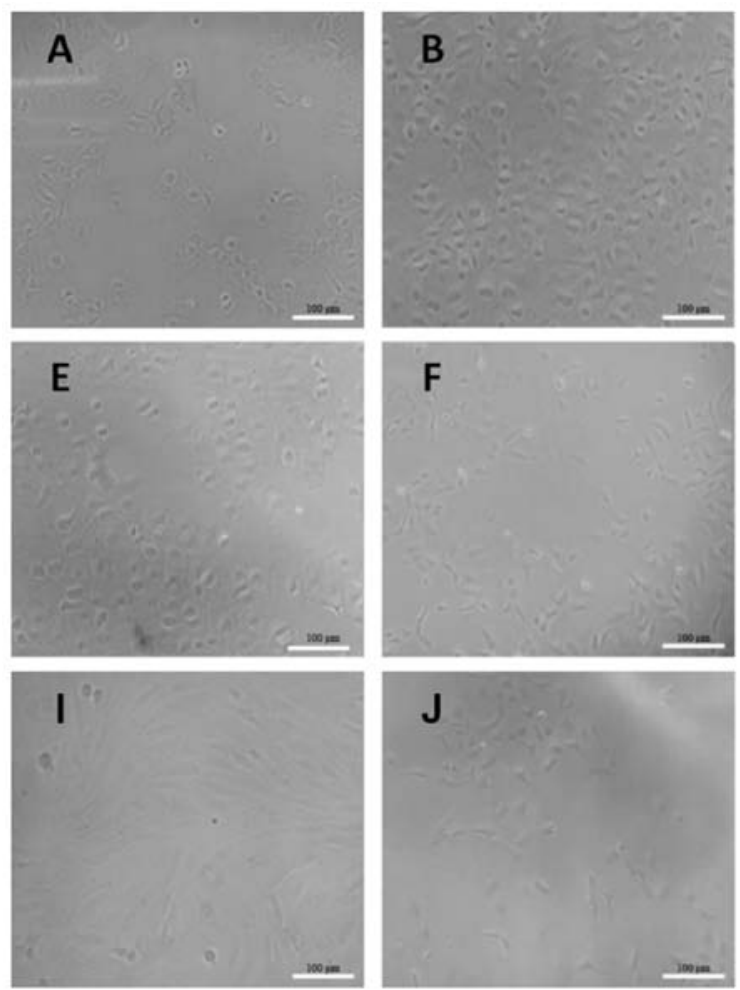
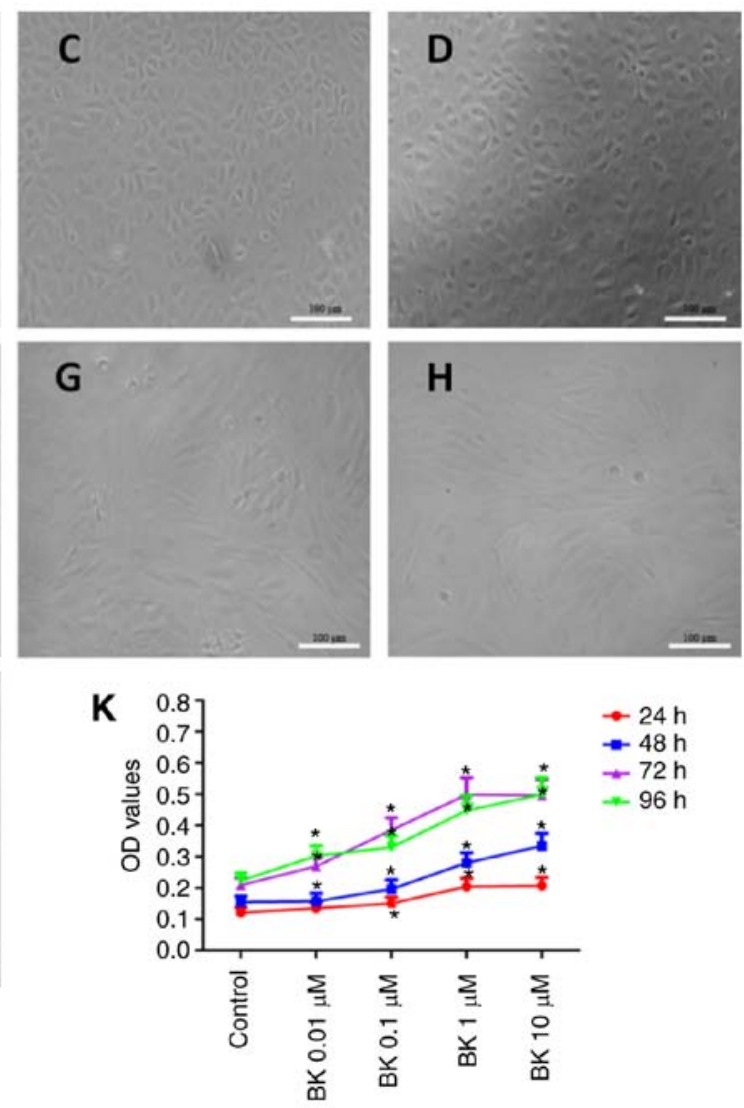

Figure 1. Time- and concentration-dependence of BK-induced proliferation in RCECs. Representative photos of RCECs under phase-contrast microscopy, following treatment with various concentrations of BK are presented (magnification, x100; scale bars, $100 \mu \mathrm{m})$. (A) Treatment without BK for $72 \mathrm{~h}$; (B) treatment with $0.01 \mu \mathrm{M}$ BK for $72 \mathrm{~h}$; (C) treatment with $0.1 \mu \mathrm{M}$ BK for $72 \mathrm{~h}$; (D) treatment with $1.0 \mu \mathrm{M}$ BK for $72 \mathrm{~h}$; (E) treatment with $10.0 \mu \mathrm{M}$ BK for $72 \mathrm{~h}$; (F) treatment without BK for $96 \mathrm{~h}$; (G) treatment with $0.01 \mu \mathrm{M} \mathrm{BK}$ for $96 \mathrm{~h}$; (H) treatment with $0.1 \mu \mathrm{M} \mathrm{BK}$ for $96 \mathrm{~h}$; (I) treatment with $1.0 \mu \mathrm{M}$ BK for $96 \mathrm{~h}$; (J) treatment with $10.0 \mu \mathrm{M}$ BK for $96 \mathrm{~h}$. (K) Analysis of cell proliferation by MTT assay. Data are expressed as the mean \pm standard deviation $\left(\mathrm{n}=5\right.$ ). ${ }^{*} \mathrm{P}<0.05$ vs. control group. BK, bradykinin; RCECs, rabbit corneal endothelial cells; OD, optical density.

ProteinTech Group, Inc.) for $1 \mathrm{~h}$ at $37^{\circ} \mathrm{C}$. An enhanced chemiluminescence system (Pierce; Thermo Fisher Scientific, Inc.) was used for measuring the protein-antibody complexes. The blots were quantified by Quantity One 1-D software (version 4.6.9; Bio-Rad Laboratories, Inc.) and $\beta$-actin was used as the control.

Immunofluorescence assay. Confluent cells were fixed in $4 \%$ paraformaldehyde in $\mathrm{PBS}, \mathrm{pH} 7.2$, for $10 \mathrm{~min}$ at $37^{\circ} \mathrm{C}$, then permeabilized in $0.1 \%$ Triton $\mathrm{X}-100$ (Sigma-Aldrich; Merck KGaA) in PBS for 5 min at room temperature; rinsed three times in PBS, and blocked for $30 \mathrm{~min}$ in PBS with $10 \%$ goat serum (Sigma-Aldrich; Merck KGaA) at $37^{\circ} \mathrm{C}$. Primary antibody staining was performed at $4^{\circ} \mathrm{C}$ overnight with the following antibodies at a 1:50 dilution: Anti-ZO-1 and anti-ZONAB. The sections were then incubated with an Alexa Fluor ${ }^{\circledR}$ 594-conjugated goat anti-mouse secondary antibody at a 1:100 dilution (cat. no. SA00006-3; ProteinTech Group, Inc.) for $2 \mathrm{~h}$ at room temperature in the dark. Following DAPI staining at $37^{\circ} \mathrm{C}$ for $10 \mathrm{~min}$, cells were imaged using an inverted fluorescence microscope (TE2000U Eclipse; Nikon Corporation).

Statistical analysis. Statistical analysis was performed using SPSS 17.0 statistical software (SPSS, Inc., Chicago, IL, USA) for Windows. All data are expressed as the mean \pm standard deviation), and analyzed via one-way analysis of variance followed by the post hoc Bonferroni's t-test where appropriate. $\mathrm{P}<0.05$ was considered to indicate a statistically significant difference.

\section{Results}

$B K$ treatment induces RCECs proliferation in a time-and concentration-dependent manner. Under an inverted microscope, cells treated with $0.1-1.0 \mu \mathrm{M}$ BK were revealed to have formed a monolayer with a mosaic arrangement, cellular morphology was normal at $72 \mathrm{~h}$ (Fig. 1A-D). However, at $96 \mathrm{~h}$, cells were irregular in shape with thin, long, neurite-like processes, and cell extensions and increased detachment were observed (Fig. 1F-J). In addition, BK increased cell density in a concentration-dependent manner when treated with 0.1-1.0 $\mu \mathrm{M} \mathrm{BK}$, while cell growth was significantly inhibited following $10.0 \mu \mathrm{M}$ BK treatment (Fig. 1A-E). Thus, BK-induced proliferation of RCECs was demonstrated to be time- and concentration- dependent.

Next, BK-induced cell proliferation was analyzed using an MTT assay. As presented in Fig. 1K, exposure of RCECs to $\mathrm{BK}$ at $0.1-1.0 \mu \mathrm{M}$ resulted in a concentration-dependent increase in optical density (OD) values, while $10.0 \mu \mathrm{M} \mathrm{BK}$ 
A

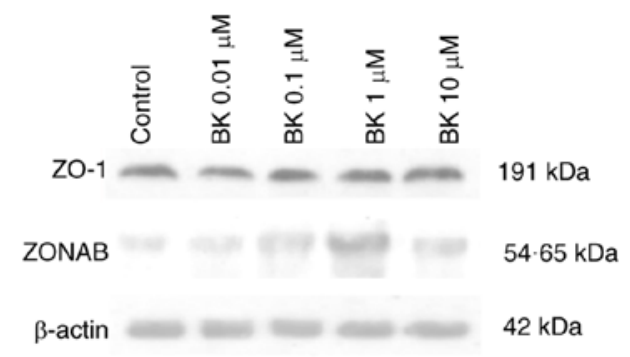

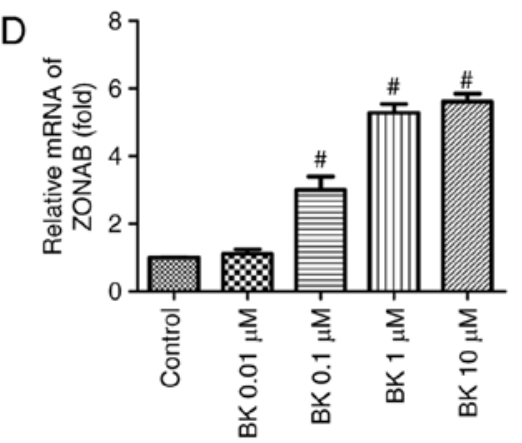

E
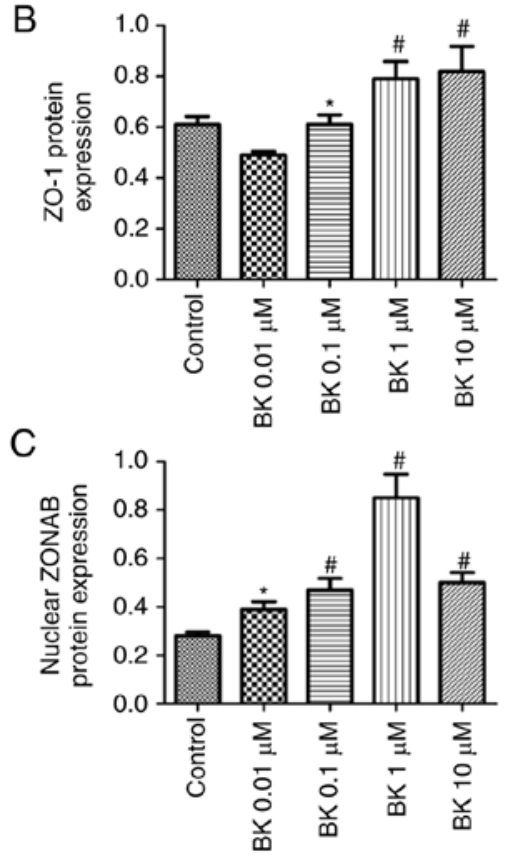

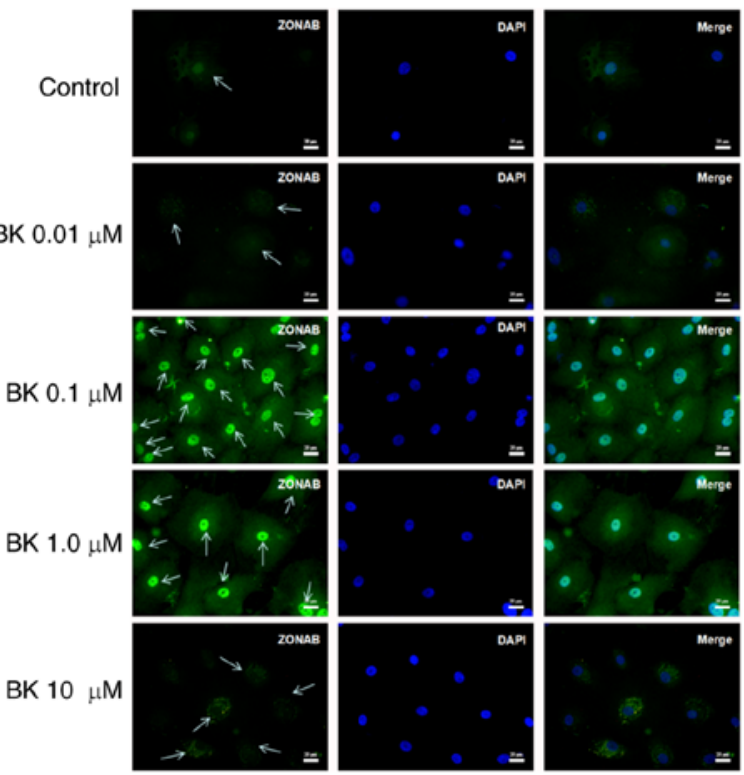

Figure 2. BK upregulated the expression of tight junction ZO-1 and nuclear ZONAB in rabbit corneal endothelial cells. (A) Representative western blotting images for ZO-1 and ZONAB, with quantification of (B) ZO-1 protein expression and (C) nuclear ZONAB protein expressions. (D) Relative ZONAB mRNA levels, as determined by reverse transcription polymerase chain reaction. (E) The localization of ZONAB was evaluated using immunofluorescence. Nuclei were counterstained with DAPI. White arrows indicate ZONAB-positive cells stained green (magnification, $\mathrm{x} 400 ;$ scale bars, $20 \mu \mathrm{m}$ ). Data are expressed as the mean \pm standard deviation $(\mathrm{n}=4)$. ${ }^{*} \mathrm{P}<0.05$ vs. control group; ${ }^{* *} \mathrm{P}<0.01$ vs. control group. BK, bradykinin; ZO-1, zonula occludens-1; ZONAB, ZO-1-associated nucleic-acid-binding protein.

treatment resulted in relatively limited proliferation, reflected by the decrease of OD values. These results indicated that BK treatment at $1.0 \mu \mathrm{M}$ significantly increased cell viability and induced RCEC proliferation.

$B K$ treatment increases the expression of the tight junction ZO-1 and nuclear ZONAB during RCECs proliferation. To determine the involvement of ZO-1 and ZONAB in the regulation of RCEC proliferation, the localization and transcription levels of ZONAB andZO-1 were assessed. Based on immunofluorescence analysis of RCECs, ZONAB was revealed to be primarily located with the nucleus or nuclear membrane, and there was high luminescence for ZONAB in these areas of cells following treatment with 0.1-1.0 $\mu \mathrm{M}$ BK and of cells in the control group, but not cells treated with $0.01 \mu \mathrm{M}$ $\mathrm{BK}$. In cells exposed to $10 \mu \mathrm{M} \mathrm{BK}$, ZONAB was primarily localized within the cytoplasm and was excluded from the nuclear region (Fig. 2E). These observations are consistent with the data from western blotting and RT-PCR. Compared with the control group, BK increased nuclear ZONAB mRNA and protein expression in a concentration-dependent manner (0.01-1.0 $\mu \mathrm{M} \mathrm{BK}$; $\mathrm{P}<0.05$ or $\mathrm{P}<0.01$; Fig. $2 \mathrm{C}$ and $\mathrm{D})$. Similarly, this BK-induced concentration-dependent effect was also was observed for ZO-1 protein (0.1-10.0 $\mu \mathrm{M}$ BK; $\mathrm{P}<0.05$ or $\mathrm{P}<0.01)$. These data suggested that $\mathrm{ZO}-1$ and $\mathrm{ZONAB}$ are crucial components in the regulation of cell proliferation in RCECs, and are potentially associated with BK-induced proliferation.

Knockdown with ZONAB siRNAs induces significant downregulation of ZONAB $m R N A$ and protein. Next, RCECs were transfected with small ZONAB-directed RNA duplexes to induce RNA interference. RT-PCR data (Fig. 3A) and western blotting analysis (Fig. 3B) suggested that transient transfection of three different regions of ZONAB resulted in efficient reduction of ZONAB $\mathrm{mRNA}$ and protein expression, while the negative control RNA duplex had no effect. In particular, transfection of the second sequence, ZONAB-siRNA2, efficiently decreased ZONAB mRNA expression with a reduction of $\sim 85 \%$ in RCECs $(\mathrm{P}<0.01$; Fig. 3A). This sequence was therefore used for the remaining experiments. 

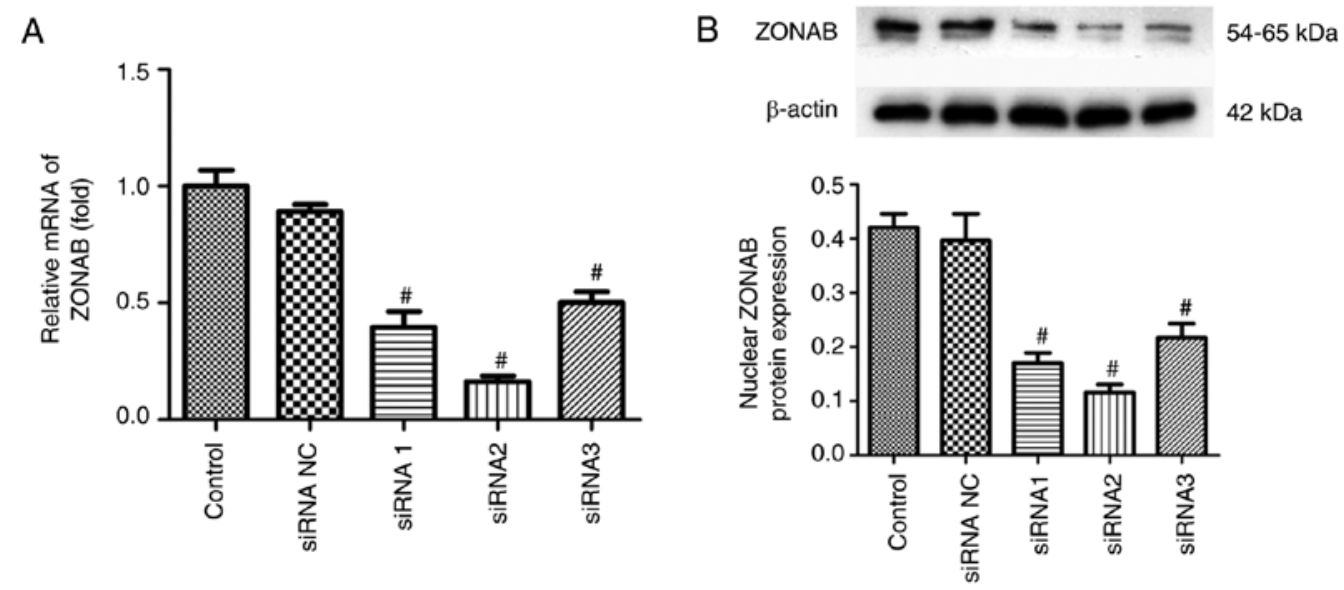

Figure 3. Knockdown of ZONAB expression in RCECs transfected with siRNAs. (A) Reverse transcription polymerase chain reaction and (B) western blotting analysis showed revealed that transfection of ZONAB siRNAs efficiently inhibited the expression of ZONAB mRNA and protein in RCECs, respectively. In particular, transfection with ZONAB-siRNA2 achieved an $\sim 85 \%$ reduction of ZONAB mRNA. Data are expressed as the mean \pm standard deviation (n=6) ${ }_{* *}^{*} \mathrm{P}<0.01$ vs. control group. ZONAB, ZO-1-associated nucleic-acid-binding protein; RCECs, rabbit corneal endothelial cells; siRNA, small interfering RNA.

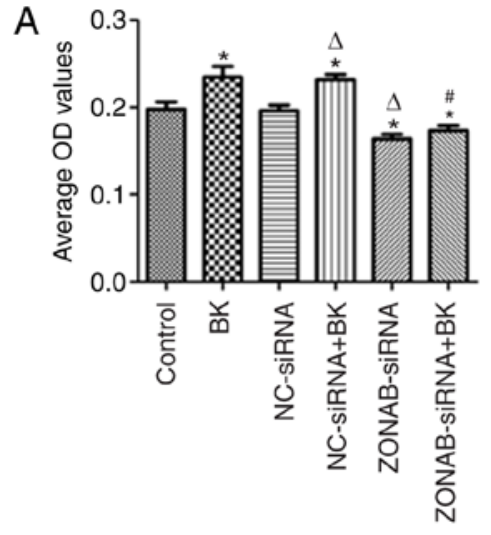

C

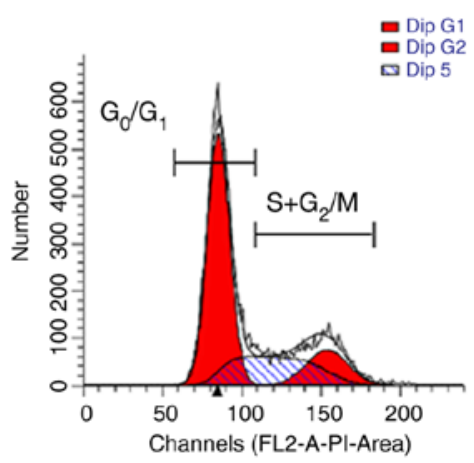

$\mathrm{F}$

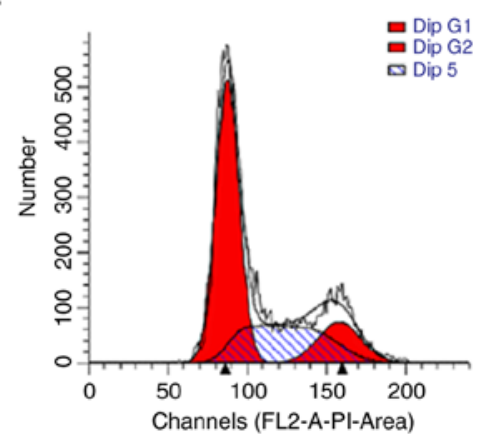

B

\begin{tabular}{rlll} 
& \multicolumn{1}{c}{$\mathrm{G}_{0} / \mathrm{G}_{1}$} & \multicolumn{1}{c}{$\mathrm{S}$} & \multicolumn{1}{c}{$\mathrm{G}_{2} / \mathrm{M}$} \\
Control & $59.65 \pm 1.94$ & $25.26 \pm 0.86$ & $15.09 \pm 0.45$ \\
$\mathrm{BK}$ & $56.60 \pm 1.23^{*}$ & $27.81 \pm 0.89^{*}$ & $15.59 \pm 0.56$ \\
NC-siRNA & $60.00 \pm 2.17$ & $25.90 \pm 0.89$ & $14.10 \pm 0.48$ \\
NC-siRNA+BK & $57.01 \pm 1.88^{*}$ & $28.25 \pm 0.96^{*}$ & $14.74 \pm 0.49$ \\
ZONAB-siRNA & $69.15 \pm 2.35^{* \Delta}$ & $18.92 \pm 0.65^{\star \Delta}$ & $11.93 \pm 0.38^{\star \Delta}$ \\
ZONAB-siRNA+BK & $64.71 \pm 2.21^{* *}$ & $20.90 \pm 0.74^{* \Delta}$ & $14.39 \pm 0.47$
\end{tabular}
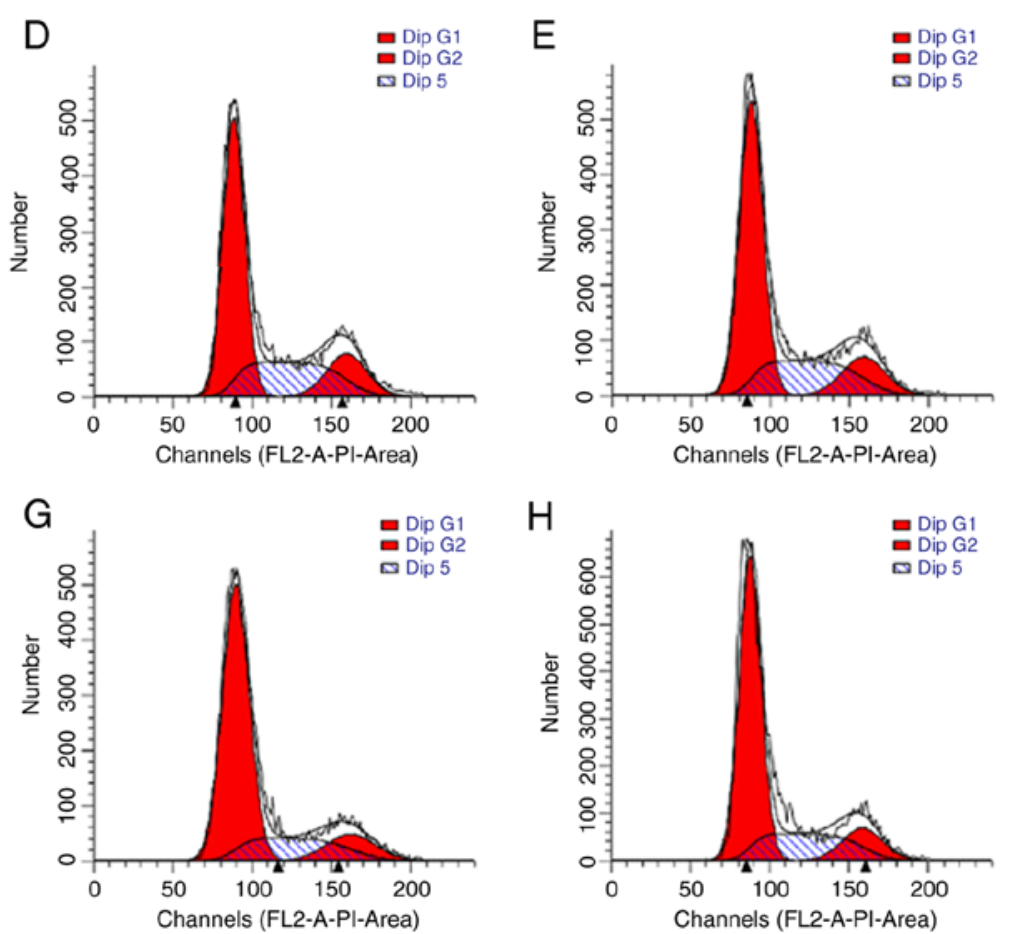

Figure 4. Knockdown with ZONAB-siRNA reversed the effect of BK on cell proliferation and cell cycle progression. (A) Cell proliferation was determined by MTT assays. (B) Table of cell cycle distribution percentages of each group. Flow cytometric analysis of cell cycle progression of rabbit corneal endothelial cells in (C) the control group, (D) the BK group, (E) the NC-siRNA group, (F) the ZONAB-siRNA group, (G) the NC-siRNA+BK group and (H) the ZONAB-siRNA+BK group. Data are expressed as the mean \pm standard deviation $(\mathrm{n}=5-6)$. ${ }^{*} \mathrm{P}<0.05$ vs. control group; ${ }^{\sharp} \mathrm{P}<0.05$ vs. $\mathrm{BK}$ group; ${ }^{\Delta} \mathrm{P}<0.05$ vs. NC-siRNA group. ZONAB, ZO-1-associated nucleic-acid-binding protein; siRNA, small interfering RNA; BK, bradykinin; NC, negative control. 

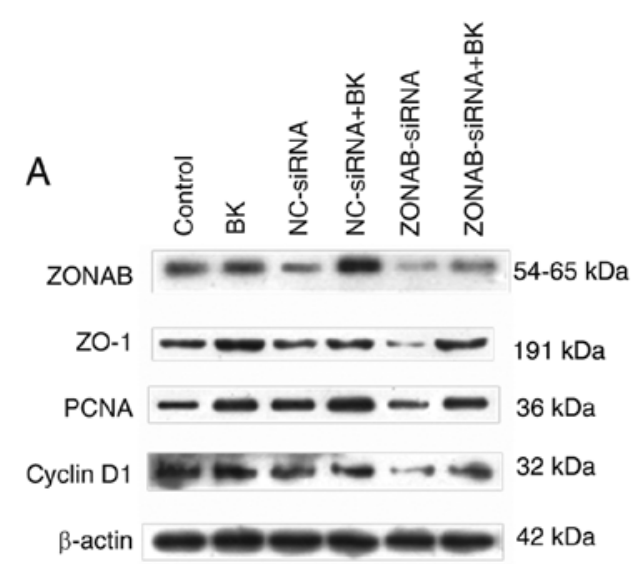

B

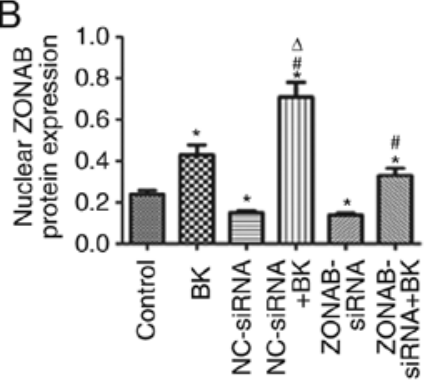

$\mathrm{D}$

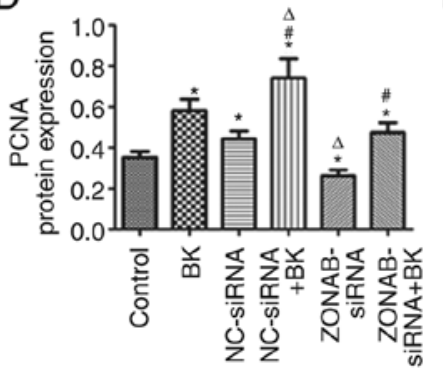

C

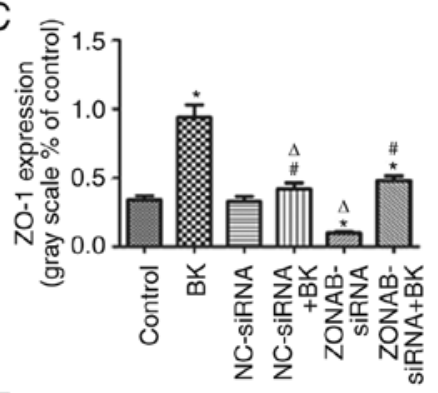

E

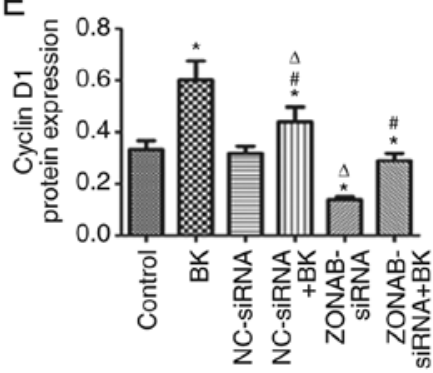

Figure 5. The involvement of the ZO-1/ZONAB pathway in BK-induced rabbit corneal endothelial cell proliferation. (A) Representative western blotting gel images. Quantification analysis of (B) ZO-1, (C) nuclear ZONAB, (D) PCNA and (E) cyclin D1. Protein expression was normalized to $\beta$-actin. Data are expressed as the mean \pm standard deviation $(\mathrm{n}=5)$. ${ }^{*} \mathrm{P}<0.05$, vs. control group; ${ }^{*} \mathrm{P}<0.05$ vs. BK group; ${ }^{\wedge} \mathrm{P}<0.05$ vs. NC-siRNA group. ZO-1, zonula occludens-1; ZONAB, ZO-1-associated nucleic-acid-binding protein; siRNA, small interfering RNA; BK, bradykinin; PCNA, proliferating cell nuclear antigen; NC, negative control.

Knockdown with ZONAB siRNAs abolishes the effect of BK on cell proliferation and cell cycle progression in RCECs. According to the MTT assay data, cells transfected with non-targeting control siRNA demonstrated proliferation capacities that were similar to those of the control group $(\mathrm{P}>0.05$; Fig. 4A). Cells lines transfected with ZONAB-siRNA exhibited lower cell proliferation and OD values than those of the control group $(\mathrm{P}<0.05$; Fig $4 \mathrm{~A})$. In contrast, a significant increase of OD value and proliferation capacity was observed in the BK-treated group compared with the control group $(\mathrm{P}<0.05$; Fig. 4A). However, proliferation significantly decreased in cells transfected with ZONAB-siRNA in combination with BK compared with those treated with $\mathrm{BK}$ alone ( $\mathrm{P}<0.05$; Fig. 4A).

Furthermore, cell cycle distribution of RCECs was quantified by flow cytometry (Fig. 4B-H). Cell cycle analysis revealed that a significantly increased fraction of cells in the $S$ phase and a significantly lower percentage of cells in the $\mathrm{G}_{0} / \mathrm{G}_{1}$ phases were present in cells treated with BK compared with the control group $(\mathrm{P}<0.05$; Fig. 4B-D). BK pretreatment accelerated the $\mathrm{G}_{1^{-}}$to $\mathrm{S}$-phase switch and enhanced DNA synthesis, thus inducing cell proliferation. Conversely, there were a larger fraction of cells arrested in $G_{0} / G_{1}$ phases and a reduction of the proportion of cells distributed in $\mathrm{S}$ phase in ZONAB-siRNA transfected cells compared with the control group ( $P<0.05$; Fig. $4 \mathrm{~B}, \mathrm{C}$ and $\mathrm{G}$ ), and a similar effect was observed in the ZONAB-siRNA+BK group compared with cells treated with $\mathrm{BK}$ alone $(\mathrm{P}<0.05$; Fig. $4 \mathrm{~B}, \mathrm{D}$ and $\mathrm{H})$. These results suggested that $\mathrm{ZONAB}$-siRNA transfection induced cell cycle arrest in $\mathrm{G}_{0} / \mathrm{G}_{1}$ phases and inhibited cell mitosis, thus reversing BK-induced proliferation of RCECs.

Involvement of the ZO-1/ZONAB pathway in BK-induced proliferation of RCECs. Finally, the regulation of the
ZO-1/ZONAB signaling cascade itself, from the upstream molecules (ZO-1 and ZONAB) to the downstream effectors (PCNA and cyclin D1) was investigated. PCNA and cyclin D1 are used as markers regulating cell proliferation and cell cycle progression in various types of cell $(25,26)$. As demonstrated by western blotting, transfection with ZONAB-siRNA resulted in knockdown of ZONAB protein levels and inhibition of PCNA and cyclin D1 expression ( $\mathrm{P}<0.05$; Fig. 5), whereas non-targeting siRNA transfection did not alter PCNA or cyclin D1 protein levels ( $\mathrm{P}>0.05$; Fig. 5 ). BK pretreatment significantly increased the expression of PCNA and cyclin D1.In turn, transfection with ZONAB-siRNA inhibited BK-induced upregulation of PCNA and cyclin D1 (P<0.05; Fig. 5), and subsequently blocked BK-stimulated cell proliferation.

\section{Discussion}

The present study initially established the involvement of the ZO-1/ZONAB pathway in BK-induced RCECs proliferation. The data revealed that $\mathrm{BK}$ promoted cell proliferation and cell cycle progression in RCECs. BK treatment also resulted in the activation of signaling molecules in the ZO-1/ZONAB pathway, including the upregulation of tight junction ZO-1 and nuclear ZONAB, as well as PCNA and cyclin D1. Furthermore, knockdown with ZONAB-siRNA inhibited cell proliferation, induced cell cycle arrest and downregulated the PCNA and cyclin D1 protein expression. Pre-treatment with siRNA to knockdown ZONAB blocked the proliferation-promoting activity of BK. Taken together, these data indicated that BK treatment increased RCECs proliferation, at least in part due to the activation of the ZO-1/ZONAB pathway.

$\mathrm{BK}$ is a well-established mediator of exudative corneal wound healing, ocular allergy and pro-inflammatory responses 
on the ocular surface (13). BK and its receptors, the B1 and $\mathrm{B} 2$ receptor, are present in the tissue homogenates of rabbit, swine and human eyes (27-29). BK interacts with its receptors on the cell surface to mediate a variety of biological effects, including cell proliferation. BK has been reported to induce proliferation of various types of cell in ex vivo corneas (8-12). However, the underlying mechanisms by which BK stimulates the proliferation of ocular cells remain to be fully understood. The majority of the biological functions of BK are mediated by the $\mathrm{B} 2$ receptor, which leads to an increase of intracellular $\mathrm{Ca}^{2+}\left(\left[\mathrm{Ca}^{2+}\right]_{\mathrm{i}}\right)$ mobilization, and tyrosine kinase and protein kinase $\mathrm{C}$ (PKC) activation via pertussis toxin (PTX)-insensitive $\mathrm{G}$ protein $(8,9,12,30,31)$. Previous reportshave suggested that BK induces cell proliferation through stimulation of phosphoinositide turnover, $\left[\mathrm{Ca}^{2+}\right]_{\mathrm{i}}$-mobilization and diacylgylcerol production, which lead to increased DNA synthesis in human corneal epithelial cells and bovine CECs $(8,9,12)$. However, pretreatment with $\mathrm{HOE}-140$, a specific B2 receptor antagonist, attenuated the BK-induced increase in $\left[\mathrm{Ca}^{2+}\right]_{\mathrm{i}}$, suggesting that $\mathrm{B} 2$ receptors serve a crucial function in this process $(8,9)$. Multiple previous studies have demonstrated that BK induces cell proliferation potentially through $\mathrm{B}_{2}$ receptor coupling PTX-sensitive G protein/ $\mathrm{Ca}^{2+} / \mathrm{PKC}$ and $\mathrm{EFGR/p42/p44}$ mitogen activated protein kinase (MAPK)-dependent pathways in various cell types (8-12,30-34). However, these mechanisms remained to be verified in CECs.

Accumulating evidence has demonstrated that the TJ-associated signaling proteins, ZO-1 and ZONAB, serve a vital role in cell proliferation, gene expression and differentiation, as reported in RPE cells and the renal proximal tubule (16-19,35-39). ZO-1 is a membrane-associated TJ adaptor protein and possesses several PDZ domains, one SH3 domain, and a domain homologous to yeast guanylate kinase $(14,40)$. ZONAB is a Y-box transcription factor that modulates cell proliferation through its interaction with the $\mathrm{SH} 3$ domain of ZO-1. ZONAB is primarily distributed in the nucleus or nuclear membrane of proliferating cells, and drives the transcription of PCNA and cyclin D1 genes for the promotion of cell proliferation and cell cycle progression (16-18). However, in slowly or non-proliferating cells, nuclear ZONAB expression is reduced, and binding of ZONAB to ZO-1 results in cytoplasmic sequestration and inhibits the nuclear accumulation and transcriptional activity of ZONAB, resulting in reduced proliferation (14-20). In the present study, with BK pre-treatment, mRNA and protein levels of nuclear ZONAB were significantly upregulated in a concentration-dependent manner, suggesting the increase of ZONAB nuclear accumulation and transcriptional activity, thus resulting in RCEC proliferation.

In the present study, the subcellular localization of ZONAB was detected by immunofluorescence. High luminescence in the nucleus indicated $\mathrm{ZONAB}$ expression following treatment with 0.1-1.0 $\mu \mathrm{M}$ BK or without $\mathrm{BK}$ in the control group, but not following treatment with $0.01 \mu \mathrm{M}$ BK. Treatment with $0.01 \mu \mathrm{M}$ BK had no effect on ZONAB nuclear translocation, and the concentration-dependent effect of $\mathrm{BK}$ on the nuclear accumulation of ZONAB was not observed. Therefore, a wide range of BK concentrations (0.0001-10 $\mu \mathrm{M})$, previously reported in human corneal epithelial cells (18), should be selected to determine the effect of BK $(<0.01 \mu \mathrm{M})$ on ZONAB nuclear distribution. In addition, the subcellular localization of ZO-1 was also analyzed. Based on previous immunofluorescence results, ZO-1 is primarily located at intercellular junctions and in the cytoplasm (16-18). While specific ZO-1 staining at intercellular junctions was not detected, ZO-1 was revealed to be distributed in the cytoplasm and nucleus (data not shown). The murine-derived monoclonal antibody against rabbit ZO-1 may have been non-specific; alternatively, ZO-1 may be sparsely distributed in the rabbit corneal endothelium. Even though the ZO-1 staining results of the present study were not satisfactory, the data suggested that the majority of ZONAB molecules bound to ZO-1 are associated with TJ, and the expression of TJ-associated molecules, ZO-1 and ZONAB, were affected by BK treatment.

Furthermore, the present study provided the evidence supporting the involvement of the ZO-1/ZONAB pathway during RCEC proliferation, as demonstrated by decreased cell proliferation, a greater fraction of cells arrested in $G_{0} / G_{1}$ phase and the downregulation of PCNA and cyclin D1 following ZONAB-siRNA transfection. These data are consistent with evidence from previous transgenic experiments. A study by Balda et al (16) demonstrated that depletion of ZONAB by RNA interference or ZO-1 overexpression reduced proliferation rates and final cell densities of Madin-darby canine kidney cells, while overexpression of ZONAB resulted in increased cell densities. Another investigation by Georgiadis et al (20) revealed that lentivirally-mediated overexpression of ZONAB or knockdown of ZO-1 resulted in an increased number of BrdU-positive cells and the induction of RPE proliferation. Kampik et al (37) revealed that knockdown of ZO-1 led to an average increase of $50 \%$ in human CECs density in corneal samples from donors $>60$ years old, while overexpression of ZONAB led to Ki67 upregulation but no significant increase in cell density. Taken together, these data suggest that ZO-1 and ZONAB are involved in signaling that modulates RCECs proliferation.

The present study investigated the function of the ZO-1/ZONAB pathway during BK-induced cell proliferation. The data revealed that transfection with ZONAB-siRNA reversed the proliferation-promoting effect of BK. Significant knockdown of ZONAB inhibited the transcriptional activity of the cell cycle genes PCNA and cyclin D1, thus attenuating BK-induced cell proliferation. Nevertheless, the exact mechanisms underlying BK-induced activation of ZO-1/ZONAB signaling remain to be fully elucidated. First, it is unclear whether the overexpression of ZONAB and knockdown of ZO-1 increase proliferation in the RCECs model utilized in the present study. Further transgenic research targeting ZO-1 and $\mathrm{ZONAB}$ is required. Second, the effect of $\mathrm{ZO}-1$ and ZONAB on CECs differentiation remains unclear, and cellular mechanisms relevant to cell differentiation should be analyzed. Third, bioinformatics analysis of ZONAB siRNA is required to minimize off-target effects resulting from the introduction of individual siRNAs. Finally, ongoing experiments by our group should be replicated in human corneal endothelia, and focus on the crosstalk between the ZO-1/ZONAB pathway and the BK-mediated $\mathrm{B}_{2}$ receptor- $\mathrm{G}$ protein $/ \mathrm{Ca}^{2+} / \mathrm{PKC}$ or EFGR-p42/p44 MAPK-dependent pathway. Further research is required to explore these areas.

In conclusion, the present study demonstrated that BK promoted RCECs proliferation and cell cycle progression, and the underlying mechanisms appeared to include the 
ZO-1/ZONAB pathway. The signaling paradigm disclosed in the present study provide novel insights and, potentially, novel therapeutic targets for cornea regeneration and transplantation.

\section{Acknowledgements}

Not applicable.

\section{Funding}

The present study was supported by the National Natural Science Foundation of China (grant nos. 81100648, 81160118 and 81400372) and the Hunan Province Education Department Outstanding Youth Science Foundation (grant no. 15B210).

\section{Availability of data and materials}

The datasets used and/or analyzed during the current study are available from the corresponding author on reasonable request.

\section{Authors' contributions}

LH and $\mathrm{ZZ}$ contributed equally to the present study. GT conceived and designed the experiments; LH, ZZ, SZ XZ and $\mathrm{YZ}$ conducted the experiments; $\mathrm{ZZ}$ and $\mathrm{SZ}$ analyzed the data; LH wrote the paper; YS and GT revised the manuscript for critically important intellectual content. All the authors read and approved the paper.

\section{Ethics approval and consent to participate}

The present study received ethical approval from the Ethics Committee of University of South China (Hengyang, China).

\section{Consent for publication}

Not applicable.

\section{Competing interests}

The authors declare that they have no competing interests.

\section{References}

1. Waring GO, Bourne WM, Edelhauser HF and Kenyon KR: The corneal endothelium. Normal and pathologic structure and function. Ophthalmology 89: 531-590, 1982.

2. Joyce NC: Proliferative capacity of the corneal endothelium. Prog Retin Eye Res 22: 359-389, 2003.

3. Bourne WM, Nelson LR and Hodge DO: Central corneal endothelial cell changes over a ten-year period. Invest Ophthalmol Vis Sci 38: 779-782, 1997.

4. Saxena R, Boekhoorn SS, Mulder PG, Noordzij B, van Rij G and Luyten GP: Long-term follow-up of endothelial cell change after Artisan phakic intraocular lens implantation. Ophthalmology 115: 608-613, 2008.

5. Kashuba E, Bailey J, Allsup D and Cawkwell L: The kinin-kallikrein system: Physiological roles, pathophysiology and its relationship to cancer biomarkers. Biomarkers 18 279-296, 2013.

6. Khan MM,Bradford HN,Isordia-Salas I,Liu Y,Wu Y,EspinolaRG Ghebrehiwet B and Colman RW: High-molecular-weight kininogen fragments stimulate the secretion of cytokines and chemokines through uPAR, Mac-1, and gClqR in monocytes. Arterioscler Thromb Vasc Biol 26: 2260-2266, 2006.
7. Levy D and Zochodne DW: Increased mRNA expression of the B1 and B2 bradykinin receptors and antinociceptive effects of their antagonists in an animal model of neuropathic pain. Pain 86: 265-271, 2000.

8. Huang SC, Chien C, Hsiao L, Wang C, Chiu C, Liang K and Yang CM: Mechanisms of bradykinin-mediated $\mathrm{Ca}^{2+}$ signaling in canine cultured corneal epithelial cells. CellSignal 13: 565-574, 2001.

9. Wiernas TK, Davis TL, Griffin BW and Sharif NA: Effects of bradykinin on signal transduction, cell proliferation, and cytokine, prostaglandin $\mathrm{E}_{2}$ and collagenase-1 release from human corneal epithelial cells. Br J Pharmacol 123: 1127-1137, 1998

10. Cheng CY, Huang SC, Hsiao LD, Sun CC, Jou MJ and Yang CM: Bradykinin-stimulated p42/p44 MAPK activation associated with cell proliferation in corneal keratocytes. CellSignal 16: 535-549, 2004.

11. Cheng CY, Tseng HC and Yang CM: Bradykinin-mediated cell proliferation depends on transactivation of EGF receptor in corneal fibroblasts. J Cell Physiol 227: 1367-1381, 2012.

12. Yang SW, Lee WK, Lee EJ, Kim KY, Lim Y, Lee KH, Rha HK and Hahn TW: Effect of bradykinin on cultured bovine corneal endothelial cells. Ophthalmologica 215: 303-308, 2001.

13. Webb JG: The kallikrein/kinin system in ocular function. J Ocul Pharmacol Ther 27: 539-543, 2011.

14. Balda MS and Matter K: Tight junctions and the regulation of gene expression. Biochim Biophys Acta 1788: 761-767, 2009.

15. Terry S, Nie M, Matter $K$ and Balda MS: Rho signaling and tight junction functions. Physiology 25: 16-26, 2010.

16. Balda MS and Matter K: The tight junction protein ZO-1 and an interacting transcription factor regulate ErbB-2 expression. EMBO J 19: 2024-2033, 2000.

17. Balda MS, Garrett MD and Matter K: The ZO-1-associated Y-box factor ZONAB regulates epithelial cell proliferation and cell density. J Cell Biol 160: 423-432, 2003.

18. Lima WR, Parreira KS, Devuyst O, Caplanusi A, N'kuli F, Marien B, Van Der Smissen P, Alves PM, Verroust P, Christensen EI, et al: ZONAB promotes proliferation and represses differentiation of proximal tubule epithelial cells. J Am Soc Nephrol 21: 478-488, 2010.

19. Sourisseau T, Georgiadis A, Tsapara A, Ali RR, Pestell R, Matter K and Balda MS: Regulation of PCNA and cyclin D1 expression and epithelial morphogenesis by the ZO-1-regulated transcription factor ZONAB/DbpA. Mol Cell Biol 26: 2387-2398, 2006.

20. Georgiadis A, Tschemutter M, Bainbridge JW, Balaggan KS, Mowat F, West EL, Munro PM, Thrasher AJ, Matter K, Balda MS, et al: The tight junction associated signaling proteins ZO-1 and ZONAB regulate retinal pigment epithelium homeostasis in mice. PloS One 5: e15730, 2010.

21. U.S. Office of Science and Technology Policy: Technology, Laboratory animal welfare; U.S. government principles for the utilization andcare of vertebrate animals used in testing, research and training; notice. Fed Regist 50: 20864-20865, 1985.

22. Kay P, Nimni ME and Smith RE: Stability of collagen phenotype in morphologically modulated rabbit corneal endothelial cells. Invest Ophthalmol Vis Sci 25: 495-501, 1984.

23. Kim TY, Kim WI, Smith RE and Kay ED: Role of p2 $7^{\mathrm{Kip} 1}$ in cAMP- and TGF- 32 -mediated antiproliferation in rabbit corneal endothelial cells. Invest Ophthalmol Vis Sci 42: 3142-3149, 2001.

24. Schäfer J, Höbel S, Bakowsky U and Aigner A: Liposomepolyethylenimine complexes for enhanced DNA and siRNA delivery. Biomaterials 31: 6892-6900, 2010.

25. Park SY, Jeong MS, Han CW, Yu HS and Jang SB: Structural and functional insight into proliferating cell nuclear antigen. J Microbiol Biotechnol 28: 637-647, 2016.

26. Qie S and Diehl JA: Cyclin D1, cancer progression, and opportunities in cancer treatment. J Mol Med) 94: 1313-1326, 2016.

27. Wiernas TK, Griffin BW and Sharif NA: The expression of functionally-coupled $\mathrm{B}_{2}$-bradykinin receptors in human corneal epithelial cells and their pharmacological characterization with agonists and antagonists. Br J Pharmacol 121: 649-656, 1997.

28. Kuznetsova TP, Chesnokova NB and Paskhina TS: Activity of tissue and plasma kallikrein and level of their precursors in eye tissue structures and media of healthy rabbits. Vopr Med Khim 37: 79-82, 1991 (In Russian).

29. Ma JX, Song Q, Hatcher HC, Crouch RK, Chao L and Chao J: Expression and cellular localization of the kallikrein-kinin system in human ocular tissues. Exp Eye Res 63: 19-26, 1996. 
30. Leeb-Lundberg LM: Bradykinin specificity and signaling at GPR100 and B2 kinin receptors. Br J Pharmacol 143: 931-932, 2004.

31. Dixon BS, Sharma RV, Dickerson T and Fortune J: Bradykinin and angiotensin II: Activation of protein kinase $\mathrm{C}$ in arterial smooth muscle. Am J Physiol 266: C1406-1420, 1994.

32. Mio T, Liu X, Toews ML, Adachi Y, Romberger DJ, Spurzem JR and Rennard SI: Bradykinin augments fibroblast-mediated contraction of released collagen gels. Am J Physiol Lung Cell Mol Physiol 281: L164-L171, 2001.

33. Bernier SG, Haldar S and Michel T: Bradykinin-regulated interactions of the mitogen-activated protein kinase pathway with the endothelial nitric-oxide synthase. J Biol Chem 275: 30707-30715, 2000.

34. Yang CM, Lin MI, Hsieh HL, Sun CC, Ma YH and Hsiao LD Bradykinin-induced p42/p44 MAPK phosphorylation and cell proliferation via Src, EGF receptors, and PI3-K/Akt in vascular smooth muscle cells. J Cell Physiol 203: 538-546, 2005.

35. Arakawa Y, Kajino K, Kano S, Tobita H, Hayashi J, Yasen M, Moriyama M, Arakawa Y and Hino O: Transcription of dbpA, a $\mathrm{Y}$ box binding protein, is positively regulated by E2F1: Implications in hepatocarcinogenesis. Biochem Biophys Res Commun 322: 297-302, 2004.

36. Jayagopal A, Yang JL, Haselton FR and Chang MS: Tight junction-associated signaling pathways modulate cell proliferation in uveal melanoma. Invest Ophthalmol Vis Sci 52 588-593, 2011
37. Kampik D, Basche M, Georgiadis A, Luhmann UF, Smith AJ, Larkin $F$ and Ali RR: Lentivirus mediated interference with the ZO-1/ZONAB pathway induces cell cycle progression in human corneal endothelial cells. Invest Ophthalmol Vis Sci 53: 6004, 2012.

38. Spadaro D, Tapia R, Jond L, Sudol M, Fanning AS and Citi S: $\mathrm{ZO}$ proteins redundantly regulate the transcription factor DbpA/ZONAB. J Biol Chem 289: 22500-22511, 2014.

39. Qiao X, Roth I, Féraille E and Hasler U: Different effects of $\mathrm{ZO}-1, \mathrm{ZO}-2$ and $\mathrm{ZO}-3$ silencing on kidney collecting duct principal cell proliferation and adhesion. Cell Cycle 13: 3059-3075, 2014.

40. Willott E, Balda MS, Fanning AS, Jameson B, Van Itallie C and Anderson JM: The tight junction protein ZO-1 is homologous to the Drosophila discs-large tumor suppressor protein of septate junctions. Proc Natl Acad Sci USA 90: 7834-7838, 1993.

This work is licensed under a Creative Commons Attribution-NonCommercial-NoDerivatives 4.0 International (CC BY-NC-ND 4.0) License. 